\title{
THE VALUE TO THE SURGEON OF PARATHYROID HORMONE ASSAYS IN PRIMARY HYPERPARATHYROIDISM
}

\author{
IAN R. GOUGH, ${ }^{1 *}$ NORMAN W. ThOMPSON ${ }^{2} \dagger$ AND Frederick E. ECKHAUSER ${ }^{2} \dagger$ \\ Departments of Surgery, *University of Queensland, Brisbane, Australia, and tSection of General \\ Surgery, The University of Michigan, Ann Arbor, Michigan, USA
}

\begin{abstract}
The role of various parathyroid hormone (PTH) radio-immunoassays in the diagnosis of primary hyperparathyroidism (PHP) is controversial. A series of 204 patients with surgically proven PHP was studied. Serum total calcium, serum ionized calcium, amino ( $N$-terminal PTH and carboxyl( $C$ )-terminal PTH were assessed in relation to the volume and weight of adenomatous or hyperplastic parathyroid tissue excised at operation. $\mathrm{N}$ terminal PTH was elevated above the normal laboratory range in only $24 \%$ of patients and correlated relatively poorly with the volume of abnormal parathyroid tissue $(r=0.20, P=0.05)$. $C$-terminal PTH was elevated above the normal range in $91 \%$ of patients and had a strong correlation with the volume of abnormal parathyroid tissue $(r=0.63, P<0.001)$. The correlation coefficients between $C$-terminal PTH and serum total calcium and serum ionized calcium were both $0.63(P<0.001)$. In contrast, there was no cotrelation hetween $N$-terminal PTH and serum total calcium $(r=-0.02)$, serum ionized calcium $(r=-0.04)$ or $C$ terminal PTH $(r=0.09)$.

A combination of hypercalcaemia and elevated $C$-terminal PTH can be regarded as strong diagnostic evidence of PHP. Furthermore, the level of $C$-terminal PTH can assist the surgeon by approximately predicting the amount of adenomatous or hyperplastic parathyroid tissue that may be expected at surgical exploration.
\end{abstract}

\section{Key words: parathyroid hormone radio-immunoassay, primary hyperparathyroidism, surgery.}

\section{Introduction}

Persistent hypercalcaemia is the characteristic biochemical abnormality in primary hyperparathyroidism (PHP). While other causes of hypercalcaemia should be considered and excluded by appropriate investigation, the availability of parathyroid hormone (PTH) assays permits a confident preoperative diagnosis of PHP to be made in most patients.

Nevertheless, since the discovery of a radioimmunoassay for PTH in 1963, the role of PTH assays in diagnosis has been controversial. ${ }^{1,2}$ The failure of many assays to reveal increased levels of PTH in some patients has led to reluctant acceptance of the combination of hypercalcaemia and 'inappropriately normal' PTH as a diagnostic feature of PHP. This unsatisfactory criterion and much of the confusion is accounted for by the multiplicity of available assays and variable laboratory techniques. ${ }^{3.4}$

PTH is secreted as a single chain polypeptide of 84 amino acids. The biological activity is believed

'FRACS. 'MD.

Correspondence: Dr Ian Gough. University Department of Surgery, Clinical Sciences Building, Royal Brisbane Hospital, Brisbane, Queensland 4029. Australia.

Accepted for publication 16 December 1987. to be contained in the 1-34 amino acids at the amino $(N)$-terminal end, this fragment having a biological half-life of a few minutes. The remainder of the molecule containing amino acids $35-84$ is referred to as the carboxyl $(C)$-terminal portion and has a half-life of approximately $1 \mathrm{~h}^{5}$

The study reported here assessed the diagnostic value of standardized assays of $C$-terminal PTH ( $C$-PTH) and $N$-terminal PTH ( $N$-PTH) in a series of 204 patients with surgically and histologically proven PHP.

\section{Methods}

The 204 patients in this series were operated on by one surgeon (NWT) using a standardized technique ${ }^{6}$ over a 5-year period to April 1984. All patients had surgically and histologically proven PHP and had been evaluated pre-operatively with either or both $C$-PTH and $N$-PTH radio-immunoassays according to the methods of Hawker et al. (Smith Kline Clinical Laboratories, Creve Coeur, Missouri). ${ }^{7}$ The PTH assay results were interpreted with reference to a normal range for $C$-PTH of $60-450 \mathrm{pg} / \mathrm{ml}$ and for $N$-PTH of $163-347 \mathrm{pg} / \mathrm{ml}$. Serum total calcium was interpreted with reference to a normal range of $8.5-10.5 \mathrm{mg} / \mathrm{dl}$ and serum ionized calcium was interpreted with reference to a normal range of 3.8- 
$4.8 \mathrm{mg} / \mathrm{dl}$. Patients who had elevated serum creatinine or PTH assayed by other methods were not included in this series.

The three diameters $\left(d_{1}, d_{2}\right.$ and $\left.d_{3}\right)$ of the parathyroid adenomas were measured and the volume of the gland (which approximates a spheroid in shape) calculated according to the formula $\pi / 6 \times$ $d_{1} \times d_{2} \times d_{3}$ and expressed in $\mathrm{mm}^{3}$. The volume of hyperplastic parathyroid tissue, when more than one gland was enlarged in an individual patient, was calculated for each gland and then the volumes were added. For each of the 204 patients, data were available for parathyroid volume and serum total calcium, and either or both $C$-PTH and $N$-PTH, on specimens taken at the same time. Serum ionized calcium data were available for 104 patients.

\section{ANALYSIS}

Initial analysis determined that logarithmic transformation of all the data for serum total calcium, serum ionized calcium, $C$-PTH, $N$-PTH and parathyroid volume provided a better approximation of a Gaussian (normal) distribution than did the raw data, and the following calculations were therefore performed with logarithmically transformed data. Correlation coefficients testing the degree of association between each of these variables were performed by regression analysis using the method of least squares. Analyses of variance were performed to assess the extent to which each variable independently predicted parathyroid volume.

\section{Results}

Data from 204 patients were analysed. All of these patients had surgically and histologically proven PHP; 196 patients had a single adenoma, three had two adenomas, and five had multiple gland hyperplasia. The volume of adenomatous or hyperplastic parathyroid tissue excised ranged from $28 \mathrm{~mm}^{3}$ to $18849 \mathrm{~mm}^{3}$ and postoperatively all patients were normocalcaemic.

There were 150 females (age range 12-87 years, mean $=56.4$ years, s.d. $=15.3$ ) and 54 males (age range $13-86$ years, mean $=49.6$ years, s.d. $=$ 15.8), the age difference being significantly different (Student's $t$ test, $t=2.75, P<0.01$ ). There was no difference in serum total calcium levels between the sexes: in the 150 females mean total calcium was $11.3 \mathrm{mg} / \mathrm{dl}$, s.d. $=1.02$, and in the 54 males mean total calcium was $11.4 \mathrm{mg} / \mathrm{dl}$, s.d. $=1.00(t=0.65,0.6>P>0.5)$. Similarly, there was no difference in parathyroid volume between the sexes: in 150 females mean volume was $1451 \mathrm{~mm}^{3}$, s.d. $=2406$, and in 54 males mean volume was $1820 \mathrm{~mm}^{3}$, s.d. $=3297 \quad(t=0.75$, $0.5>P>0.4$ ).

C-PTH was assayed in 185 patients. It was normal in 17 and elevated above the normal range in
$168(91 \%)$. Again, there was no difference in $C$ PTH between the sexes: in the 138 females mean $C$ PTH was $1664 \mathrm{pg} / \mathrm{ml}$, s.d. $=2984$ and in the 47 males mean $C$-PTH was $1357 \mathrm{pg} / \mathrm{ml}$, s.d. $=1036$ $(t=1.04,0.3>P>0.2) . N$-PTH was assayed in 95 patients and was normal in 71 , low in one and elevated above the normal range in $23(24 \%) . N$ PTH was elevated in only two of the patients in whom $C$-PTH was normal.

The value of $C$-PTH in patients with marginal hypercalcaemia (serum total calcium of $10.7 \mathrm{mg} / \mathrm{dl}$ or less) was examined and was found to be normal in 12 and increased in $46(79 \%), C$-PTH in patients with serum total calcium of $10.8 \mathrm{mg} / \mathrm{dl}$ or more was normal in five and increased in $122(96 \%)$. This difference was significant $\left(\chi^{2}=13.38, P<0.001\right)$.

All of the patients had elevated serum total calcium on at least one test, but on the sample of blood on which the simultaneous total calcium and PTH was measured, 47 had serum total calcium levels in the normal range (that is, $77 \%$ were elevated). There were 104 patients who had both total and ionized calcium measured simultaneously and of these serum ionized calcium was normal in 25 and elevated in $79(76 \%)$. Thirteen patients had normal levels of both total and ionized calcium, 18 had normal total calcium and elevated ionized calcium, 12 had elevated total calcium and normal ionized calcium, and 61 had elevated levels of both.

There was a strong positive correlation between the level of $C$-terminal PTH and the volume of abnormal parathyroid tissue $(r=0.63, P<0.001)$. In contrast, the correlation between the level of $N$-terminal PTH and the volume of abnormal parathyroid tissue was relatively weak $(r=0.20$, $P=0.05$ ). There was good correlation between $C$-PTH and serum total calcium (185 patients) and $C$-PTH and serum ionized calcium ( 89 patients), the values being the same for both $(r=0.63$. $P<0.001$ ). In contrast, there was no correlation between $N$-PTH and serum total calcium $(r=$ $-0.02), N$-PTH and serum ionized calcium $(r=$ $-0.04)$ or $N$-PTH and $C$-PTH $(r=0.09)$. Table 1 shows a correlation matrix of logarithmically transformed data in 51 patients in whom total calcium, ionized calcium, $C$-PTH and $N$-PTH were all available from the same blood specimen.

Analyses of variance were performed to assess the extent to which each of the other three variables

Table 1. Correlation matrix of logarithmically transformed data

Total calcium Ionized calcium N-PTH

\begin{tabular}{lrrr}
\hline lonized calcium & 0.65 & & \\
$N$-PTH & -0.02 & -0.04 & \\
$C$-PTH & 0.52 & 0.62 & 0.09
\end{tabular}


predicted volume independently of $C$-PTH. The correlation between log volume and log total calcium, serum ionized calcium and $N$-PTH, after adjusting for $C$-PTH (fitting a linear model to $C$ PTH) was $0.01,0.05$ and 0.09 respectively. None of these was significantly different from zero and therefore none could be used to improve the prediction of volume based on $C$-terminal PTH. The relationship of $\log C$-PTH to $\log$ volume is shown (Fig. 1). The upper and lower lines indicate the $95 \%$ confidence limits for volume for any known value of $C$-PTH.

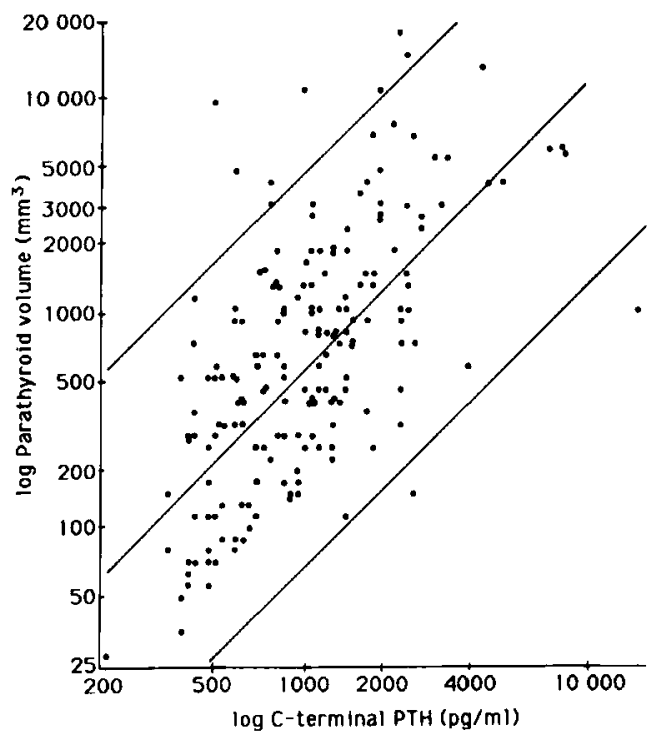

Fig. 1. Correlation between $\log$ C-terminal PTH and $\log$ volume of adenomatous or hyperplastic parathyroid tissue ( $r=0.63, P<0.001)$. 95\% confidence limits are indicated by the upper and lower lines.
The weight of abnormal parathyroid tissue was available in 48 patients and the range was 65 $20000 \mathrm{mg}$ (mean $=1841 \mathrm{mg}$, s.d. $=3557)$. The volume of abnormal parathyroid tissue in these patients correlated very strongly with the weight $(r=0.90, P<<0.001)$.

The number of false negative and false positive diagnoses which may have occurred during the time this series was collected was not accurately known and therefore the sensitivity and specificity of the diagnostic tests could not be calculated. Three additional patients with hypercalcaemia and elevated $C$-PTH during the time this series was collected probably had PHP but were not included in the analysis because their treatment and its outcome were not finalized.

\section{Discussion}

The results of this study show that the $C$-PTH assay was a valuable aid to diagnosis in patients with suspected PHP. In contrast, the $N$-PTH assay was of little diagnostic value and the results of this assay may even confuse the diagnosis.

The results of previously published clinical studies of PTH assays are summarized in Tables 2 and 3 . In these studies, $\dot{C}$-PTH assays were elevated above the normal range in $87 \%$ of patients, and $N$-PTH assays were elevated in $67 \%$. Four of the studies involved comparisons of $C$ - and $N$-PTH assays and in each of these the $C$-PTH assay appeared to be superior. $9,10,13,14$

There are several methods of assay for $C$ - and $N$-PTH, and there are, in addition, other assays towards different aspects of the PTH molecule. Some of these assays have not been well-characterized. Heterologous PTH assays directed towards both $C$ and $N$-PTH have been reported to be elevated in 11 of 19,2241 of $56,,^{23}$ and 18 of $34^{20}$ patients with PHP, but these assays have not been widely used.

Table 2. $C$-terminal PTH assays in primary hyperparathyroidism

\begin{tabular}{|c|c|c|c|}
\hline Year & Author & Number of patients & Number with elevated PTH \\
\hline 1968 & Reiss and Canterbury ${ }^{8}$ & 32 & 32 \\
\hline 1973 & Silverman and Yalow ${ }^{9}$ & 13 & 11 \\
\hline 1974 & Arnaud et al. & 38 & 35 \\
\hline 1974 & Conaway and Anast ${ }^{\text {II }}$ & 29 & 27 \\
\hline 1978 & Di Bella et al. ${ }^{12}$ & 73 & 70 \\
\hline 1979 & Raisz et al. ${ }^{13}$ & 45 & 29 \\
\hline 1980 & Simon and Cuan ${ }^{14}$ & 29 & 13 \\
\hline 1981 & Kao et al. ${ }^{15}$ & 112 & 100 \\
\hline 1981 & Roos et al..$^{16}$ & 16 & 14 \\
\hline \multirow[t]{2}{*}{1981} & Freaney et al. ${ }^{17}$ & 51 & 49 \\
\hline & & 438 & 380 \\
\hline
\end{tabular}


Table 3. $N$-terminal PTH assays in primary hyperparathyroidism

\begin{tabular}{llrr}
\hline Year & Author & Number of patients & Number with elevated PTH \\
\hline 1973 & Silverman and Yalow & 13 & 3 \\
1974 & Arnaud et al. ${ }^{10}$ & 35 & 21 \\
1974 & Woo and Singer $^{18}$ & 22 & 19 \\
1976 & Samaan et al. $^{19}$ & 82 & 62 \\
1979 & Raisz et al. $^{13}$ & 15 & 6 \\
1980 & Simon and Cuan $^{14}$ & 18 & 6 \\
1980 & Papapoulos et al. & 34 & 28 \\
1981 & Lafferty & 100 & 64 \\
& & 301 & 203 \\
\hline
\end{tabular}

Other assays directed towards the mid-region of the PTH molecule have been described and the early results appear to be encouraging. ${ }^{16,24}$ More recently, apparently sensitive and specific double antibody assays for the 'intact' PTH molecule have been developed. It seems likely that progressive improvement in assays will occur and the former unsatisfactory status of PTH assays will be resolved favourably.

The present study represents the largest series of patients with proven PHP in which the diagnostic value of $C$-PTH and $N$-PTH assays has been evaluated. The results indicate that $C$-PTH was elevated in $91 \%$ of patients, while $N$-PTH was elevated in only $24 \%$, C-PTH was strongly positively correlated with the volume of adenomatous or hyperplastic parathyroid tissue, but $N$-PTH was only weakly correlated with parathyroid volume. Furthermore, $N$-PTH was negatively correlated with serum total calcium and serum ionized calcium and did not correlate with $C$-PTH. It can therefore be concluded that the $N$-PTH assay used in this study was of little diagnostic value, and if it had been the only assay used would have been falsely negative in about $75 \%$ of patients. Although $N$-PTH assays have limited value in the diagnosis of PHP, they may still have a potential role in selective venous catheterization for the location of parathyroid adenomas not found at the first operation, in the evaluation of secondary hyperparathyroidism in renal failure and in the assessment of parathyroid autograft function,

It would be expected from the demonstrated correlations that $C$-PTH levels would tend to be lower in patients with lower levels of serum total calcium. It is well-recognized that some patients with asymptomatic PHP and even some of those with symptoms or complications such as renal calculi may have mild or intermittent hypercalcaemia. It was therefore of interest to examine more closely the $C$-PTH results in patients with serum total calcium of $10.7 \mathrm{mg} / \mathrm{dl}$ or less on the simultaneous blood specimen. Although there was a significantly greater proportion of false negative results, the fact that $79 \%$ of results were abnormally elevated indicates that the $C$-PTH assay should be of diagnostic value in the majority of even this difficult group of patients. It should therefore be rarely necessary in the future to base a diagnosis of PHP on the combination of hypercalcaemia and an inappropriately normal PTH assay.

In this series the ratio of females:males was 2.8:1, compared with ratios of $2: 1$ and 2.6:1 in other large series. ${ }^{25,26}$ The females, as would be anticipated, were on average 6 years older than the males, but there were no other differences regarding serum total calcium, serum $C$-PTH or parathyroid volume, indicating that the $C$-PTH assay is likely to be useful in males and females of all ages. Single adenomas were found in $96 \%$ of patients compared with an incidence of $80 \%$ in a previous series from the University of Michigan Hospitals, ${ }^{27}$ and incidences of approximately $76 \%$ in other large series. ${ }^{25,26}$ This pattern of pathology would not influence the results of the study because the data were analysed using the volume of adenomatous or hyperplastic parathyroid tissue as the standard.

Although serum ionized calcium has been reported to be helpful in the diagnosis of PHP when the serum total calcium levels are near the upper limit of normal, ${ }^{28}$ it provided no additional information in the present study.

$C$-PTH was shown to correlate strongly with parathyroid volume and therefore it was of interest to plot the volume of adenomatous or hyperplastic parathyroid tissue relative to levels of $C$-PTH. A similar exercise has been reported previously relating the mass of excised phaeochromocytoma tissue to levels of urinary vanillyl mandelic acid excretion. ${ }^{29} \mathrm{~A}$ recent study of pre-operative serum calcium and PTH levels concluded that identification of the pathological parathyroid glands in PHP could not be based on the demonstrated relationship between the results of these tests and the size of the enlarged glands because the correlations were not sufficiently strong. ${ }^{30}$ These authors reviewed 92 patients and found correlations between serum calcium and parathyroid weight $(r=0.14, P<0.001)$ 
and volume $(r=0.144, P<0.001)$. They also found stronger correlations between immuno-PTH levels by three different assays and parathyroid weight $(r=0.25,0.4,0.44$, all $P<0.001)$ and volume ( $r=0.25,0.26,0.44$, all $P<0.001)$.

The most important factor in determining the success of parathyroid surgery is the thoroughness of the dissection by an experienced surgeon. However, the level of a reliable PTH assay, as shown in the present study, can be of some assistance to the surgeon. Volume in $\mathrm{mm}^{3}$ and weight in $\mathrm{mg}$ are approximately equal and can be regarded as equivalent for practical purposes. The surgeon can obtain some guidance by reference to data such as in Fig. 1. If the minimum volume (or weight) is not accounted for by the tissue identified then surgical exploration should probably continue. For example, if the patient had a C-PTH level of $2000 \mathrm{pg} / \mathrm{ml}$ there would be a $95 \%$ probability that at least $150 \mathrm{mg}$ of abnormal parathyroid tissue was present and a $90 \%$ probability that at least $200 \mathrm{mg}$ was present.

This study showed that a $C$-PTH assay was elevated in $91 \%$ of patients with PHP. The $C$-PTH assay correlated well with the amount of adenomatous or hyperplastic parathyroid tissue excised at operation. The combination of hypercalcaemia and elevation of a sensitive $C$-PTH assay is therefore strong diagnostic evidence of PHP, and the levels in an individual patient can give the surgeon some guidance by approximately predicting the amount of abnormal parathyroid tissue which should be identified at operation.

\section{Acknowledgment}

The authors acknowledge Professor Edward Rothman PhD of the Department of Statistics, The University of Michigan, Ann Arbor, Michigan, USA who assisted with the statistical analysis.

\section{References}

1. Berson S. A., Yalow R. S., Aurbach G. D. \& Potrs J. T. (1963) Immunoassay of bovine and human parathyroid hormone. Proc. Nat. Acad. Sci. 49, 613-7.

2. Ralsz L. G, (1971) The diagnosis of hyperparathyroidism (or what to do until the immunoassay comes). N. Engl. J. Med. 285, 1006-10.

3. European PTH S Tudy Group (1978) Interlaboratory comparison of radioimmunological parathyroid hormone determination. Eur. J. Clin. Invest. 8, 149-54.

4. Gorog R. H., Hakim M. K., Thompson N. W., Rigg G. A. \& MCCANN D. S. (1982) Radioimmunoassay of serum parathyrin: comparison of five commercial kits. Clin. Chem. 28, 87-91.

5. Hawker C. D., Clark S. W., Martin K. J., Slatopolsky E. \& Di Bella F. P. (1983) Radioimmunoassay of parathyroid hormone: clinical utility and interpretation. In: Endocrine Surgery Update, (Eds N. W. Thompson \& A. I. Vinik) pp. 321-40. Grune and Stratton, New York.

6. Thompson N. W. (1983) The techniques of initial parathyroid exploration and reoperative parathyroidectomy. In: Endocrine Surgery Update (Eds N. W. Thompson \& A. 1. Vinik), pp. 365-83. Grune and Stratton, New York.

7. Di Bella F. P. \& Hawker C. D. (1982) Parathyrin (parathyroid hormone): Radioimmunoassays for intact and carboxyl-terminal moieties. Clin. Chem. 28, 226-35.

8. Reiss E. \& Canterbury J. M. (1968) A radioimmunoassay for parathyroid hormone in man. Proc. Soc. Exp. Biol. Med. 128, 501-4.

9. Silverman R. \& Yalow R. S. (1973) Heterogeneity of parathyroid hormone: clinical and physiological implications. J. Clin. Invest. 52, 1958-71.

10. Arnaud C. D., Goldsmith R. S., Bordier P. J., Sizemore G. W., LaRsen J. A. \& Gilkinson J. (1974) Influence of immunoheterogeneity of circulating parathyroid hormone on results of radioimmunoassays of serum in man. Amer. J. Med. 56, 785-93.

11. Conaway H. H., Anast C. S. (1974) Doubleantibody radioimmunoassay for parathyroid hormone. J. Lab. Clin. Med. 83, 129-38.

12. Di Bella F. P., Kehrwald J. M., Laakso K. \& ZITNER L. (1978) Parathyrin radioimmunoassay: diagnostic utility of antisera produced against carboxyl-terminal fragments of the hormone from the human. Clin. Chem. 24, 451-4.

13. RAISz L. G., Y AJNIK C. H., BockMAN R. S. \& Bower B. F. (1979) Comparison of commercially available parathyroid hormone immunoassays in the differential diagnosis of hypercalcemia due to primary hyperpara-thyroidism or malignancy. Ann. Intern. Med. 91, 739-40.

14. Simon M. \& Cuan J. (1980) Diagnostic utility of $C$ terminal parathyrin measurement as compared with measurements of $N$-terminal parathyrin and calcium in serum. Clin. Chem. 26, 1672-6.

15. Kao P. C., Jiang N. S., Klee G. G. \& Purnell D. C. (1982) Development and validation of a new radioimmunoassay for parathyrin (PTH). Clin. Chem. 28, $69-74$.

16. Roos B. A., Lindall A. W., Aron D. C., et al. (1981) Detection and characterization of small midregion parathyroid hormone fragment(s) in normal and hyperparathyroid glands and sera by immunoextraction and region-specific radioimmunoassays. J. Clin. Endocrinol. Metab. 53, 709-21.

17. Freaney R., Ryan E. \& Muldowney F. P. (1981) Differentiation of hyper-calcaemia due to malignancy from primary hyperparathyroidism: the value of parathyroid hormone and plasma bicarbonate measurements. Irish J. Med. Sci. 150, 6-12.

18. Woo J. \& Singer F. R. (1974) Radioimmunoassay for human parathyroid hormone. Clin. Chim. Acta 54, 161-8.

19. Samaan N. A., Hickey R. C., Sethi M. R., Yang K. P. \& Wallace S. (1976) Hypercalcemia in patients with known malignant disease. Surgery 80, 382-9.

20. Papapoulos S.E., Manning R. M., Hendy G. N., Lewin I. G. \& O'RIordan J. L. H. (1980) Studies of 
circulating parathyroid hormone in man using a homologous amino-terminal specific immunoradiometric assay. Clin. Enocrinol. 13, 57-67.

21. LAFFerTy F. W. (1981) Primary hyperparathyroidism: Changing clinical spectrum, prevalence of hypertension, and discriminant analysis of laboratory tests. Arch. Intern. Med. 141, 1761-6.

22. Potrs J. T., Murray T. M., Peacock M., et al. (1971) Parathyroid hormone: Sequence, synthesis, immunoassay studies. Amer. J. Med. 50, 639-49.

23. Broadus A. E., Mahaffey J. E., Bartter F. C. \& NeER R. M. (1977) Nephrogenous cyclic adenosine monophosphate as a parathyroid function test. $J$. Clin. Invest. 60, 771-83.

24. Marx S. J., Sharp M. E., Krudy A., Rosenblatt M. \& Mallette L. E. (1981) Radio-immunoassay for the middle region of human parathyroid hormone: studies with a radioiodinated synthetic peptide. $J$. Clin. Endocrinol. Metab. 53, 76-84.

25. Cowie A. G. A. (1982) Morbidity in adult parathyroid surgery. J. Roy. Soc. Med. 75, 942-5.
26. Russell C. F. \& EDIS A. J. ( 1982) Surgery for primary hyperparathyroidism: experience with 500 consecutive cases and evaluation of the role of surgery in the asymptomatic patient. Br. J. Surg. 69, 244-7.

27. Thompson N. W., Eckhauser F. E. \& Harness J. K (1982) The anatomy of primary hyperparathyroidism. Surgery 92, 814-21.

28. McLeod M. K., Monchik J. M. \& Martin H. F. (1984) The role of ionized calcium in the diagnosis of subtle hypercalcemia in symptomatic primary hyperparathyroidism. Surgery 95, 667-73.

29. Farndon J. R., Davidson H. A., Johnston I. D. A. \& Wells S. A. (1980) VMA excretion in patients with pheochromocytoma. Ann. Surg. 191, 259-63.

30. Rutledge R., Stiegel M., Thomas C. G. JR \& Wild R. E. (1985) The relation of serum calcium and immunoparathormone levels to parathyroid size and weight in primary hyperparathyroidism. Surgery 98, $1107-12$. 